\title{
Transforming landscapes and mindscapes through regenerative agriculture
}

\author{
Ethan Gordon ${ }^{1}\left[\right.$ [ Federico Davila ${ }^{1}\left[\right.$ Chris Riedy $^{1}[$
}

Accepted: 5 October 2021 / Published online: 2 November 2021

(c) Crown 2021

\begin{abstract}
Agriculture occupies $38 \%$ of the planet's terrestrial surface, using $70 \%$ of freshwater resources. Its modern practice is dominated by an industrial-productivist discourse, which has contributed to the simplification and degradation of human and ecological systems. As such, agricultural transformation is essential for creating more sustainable food systems. This paper focuses on discursive change. A prominent discursive alternative to industrial-productivist agriculture is regenerative agriculture. Regenerative discourses are emergent, radically evolving and diverse. It is unclear whether they have the potential to generate the changes required to shift industrial-productivist agriculture. This paper presents a literature-based discourse analysis to illustrate key thematic characteristics of regenerative agricultural discourses. The analysis finds that such discourses: situate agricultural work within nested, complex living systems; position farms as relational, characterised by co-evolution between humans and other landscape biota; perceive the innate potential of living systems as place-sourced; maintain a transformative openness to alternative thinking and practice; believe that multiple regenerative cultures are necessary for deeply regenerative agriculture; and depart from industrialism to varying degrees. The paper concludes by reviewing three transformative opportunities for regenerative discourses-discourse coalitions, translocal organising and collective learning.
\end{abstract}

Keywords Regenerative agriculture $\cdot$ Regenerative discourses $\cdot$ Transformations $\cdot$ Regenerative development $\cdot$ Discourse coalitions

\section{Introduction: transforming the dominant, industrial-productivist agriculture}

Without significant change in the agricultural sector worldwide, human activities will continue to overstep planetary boundaries (Rockström et al. 2016; Campbell et al. 2017). Having entered a new epoch known as the Anthropocene (Steffen et al. 2007, 2011; Crutzen 2002, 2016), humans are now the leading drivers of change to earth systems (Rockstrom et al. 2009a). Agriculture occupies 38\% of the planet's

Ethan Gordon

ethan.gordon@uts.edu.au

Federico Davila

federico.davila@uts.edu.au

Chris Riedy

christopher.riedy@uts.edu.au

1 Institute for Sustainable Futures, University of Technology Sydney, Bldg 10, 235 Jones St, Ultimo, NSW 2007, Australia terrestrial surface (Massy 2013; Zhang et al. 2007; Foley et al. 2011), making it a dominant driver of change in global ecosystems. According to Campbell et al. (2017), human agricultural activity contributes significantly to actual or projected overstepping of several planetary boundaries, including biogeochemical flows, biosphere integrity, landsystems change, freshwater use and climate change. As such, the agricultural sector has a role to play in preventing further oversteps and bringing humanity back within planetary boundaries (Gerten et al. 2020; Springman et al. 2018; IPCC 2019).

Modern agriculture operates on an industrial scale, relying on fossil fuel inputs, multinational companies and artificial fertilisers, pesticides and herbicides to grow output (McNeill 2000; Kimbrell 2002; Knorr 1984). It is inherently productivist (McKeon 2015; Argent 2002; Gosnell et al. 2019; Lawrence et al. 2013), defined by Lowe et al. (1993, p. 221) as committed "to an intensive, industrially driven and expansionist agriculture with state support based primarily on output and increased productivity." As Gliessman (2007) 
points out, the dominant mode of agriculture is obsessed with the maximisation of profit and production. Its industrial character is extractive (Anderson and Revera-Ferre 2021), signposted by large scale, capital-intensive and mechanised practices (Knorr 1984). These include synthetic fertiliser use (Pimentel et al. 1991; Pimentel 2005), chemical control (Carson 1962 (1972 repr.)), genome manipulation (Rowell 2003), monocultural production (Knorr 1984), tillage (Massy 2013) and factory farming (Massy 2013) or intensive animal husbandry (Knorr 1984). The implementation and integration of these practices has, "simplified agricultural systems in ways that are having alarming consequences on the health of people and landscapes" (Provenza 2008, pp. 277-278). Due to its mass uptake, industrial agriculture has become synonymous with the term 'conventional.' However, the use of chemicals and synthetic fertilisers is a postwar phenomenon (Zimmer 2000). Ironically, relative to the period of time that humans have been practicing agriculture, it's these conventional approaches that are still new on the agricultural scene.

For the purposes of this paper, the dominant mode of agriculture will be referred to as 'industrial-productivist' because of its aforementioned commitment to increased production, profit and mechanisation. COVID-19 illustrated the weaknesses of industrial-productivist agriculture as the economic fallout resulted in a swift disruption of food production, processing, distribution and consumption (Van der Ploeg 2020). This agricultural model also degrades socioecological systems (Campbell et al. 2017; Horrigan et al. 2002). Table 1 summarises this degradation using landscape processes as a heuristic tool for illustrating the challenges of industrial-productivist agriculture. These processes were originally articulated by Savory (2016) and further contributed to by Massy (2013). They provide a useful framework for organising evidence that suggests the industrial-productivist model needs to be transformed.

Agricultural transformation must deal with the structural and systemic drivers eroding agricultural systems (Vermeulen et al. 2019). Transformation is defined as a, "deep and sustained, nonlinear systemic change, generally involving cultural, political, technological, economic, social and/ or environmental processes" (Linnér and Wibeck 2020, p. 222). This definition demonstrates that transformation is not limited to change in material systems and landscapes; it also involves change in shared socio-cultural structures (Linnér and Wibeck 2020). While there are many ways to describe the socio-cultural world, a common focus is on discoursesthe shared cultural structures that influence how we perceive and construct technologies, institutions and practices (Linnér and Wibeck 2019; Fazey et al. 2018; Riedy 2020). Discourses shape the way people conceptualise reality (Dryzek 2013), making up a collective 'mindscape' that interacts with the material world. As such, shifting mindscapes has been identified as a possible, and perhaps necessary, transformative intervention towards sustainability (Linnér and Wibeck 2020; Scrutton et al. 2020; Meadows 2008).

The aim of this paper is to explore opportunities to transform the industrial-productivist discourse that currently dominates agricultural mindscapes. Specifically, we examine one of the most prominent emerging discursive alternatives-regenerative agriculture. It is important to note that regenerative discourses go beyond agriculture and reflect shared patterns for understanding the process of regeneration. However, this paper is concerned with the manifestation of regenerative discourses in an agricultural context. We are aware that broader regeneration work might impact how the discourses manifest within regenerative agriculture and this informed our analysis. We identify the thematic characteristics of regenerative agricultural discourses and assess whether these offer opportunities for transforming industrial-productivist agriculture. The next section outlines the discursive commitments of regenerative agriculture in more detail.

\section{Regenerative agriculture as a possible alternative}

Given the negative impacts of industrial-productivist agriculture, there is an urgent need to explore alternative agricultural approaches that can support transformations (Van der Ploeg 2020; Bene 2020). Many alternatives have been documented, such as agroecology (Gliessman 1990, 2001, 2007; Altieri 1995; Iles 2020; Conway 1985, 1987), permaculture (Mollison 1988; Holmgren 2007), carbon farming (Baumber et al. 2019, 2020; Toensmeier 2016; Ridinger 2016), natural farming (Fukuoka 1978), keyline farming (Yeomans 1993), organic agriculture (Howard 2013, 1940; Leu 2020), biodynamic agriculture (Steiner 1993), Indigenous land stewardship (Gammage 2011; Pascoe 2014; RomeroBriones et al. 2020), climate smart agriculture (Codur and Watson 2018) and holistic management (Savory and Butterfield 2016, 1999; Savory 1988; Gosnell et al. 2020b) or adaptive management (Hodbod et al. 2016; Teague and Barnes 2017; Teague and Kreuter 2020). These alternatives have developed their own discourses, communities of practice and underlying philosophies that challenge extractive food systems. Another prominent and growing alternative has emerged in the thinking and practice of regenerative agriculture.

Regenerative agriculture seeks continual renewal of agricultural systems, from soil through to people (Hes and Rose 2019). It is committed to restoring damaged landscapes and realising their innate potential (Massy 2017, 2013; Francis and Harwood 1985). However, there is variation in how this shared discursive commitment is pursued (Grelet 
Table 1 Degradation through industrial-productivist agriculture

Landscape processes as identified by Savory and Butterfield (1999, 2016); contributed to by Massy (2013)

Soil-mineral cycle: the cyclical pattern of minerals and nutrients being used and reused by living organisms (particularly implying a biologically active soil)

Water cycle: the fixed amount of water available that cycles through landscapes, oceans and the atmosphere

Community-ecosystem dynamics: the ever-changing patterns in how a collection of organisms (that exist in a particular locality), relate to one another

Solar-energy flow: the cycle of energy from the sun into all living and non-living things, through a plant's capacity for photosynthesis

There is acknowledgement that agriculture is a social and cultural activity that both shapes and is shaped by landscapes (McIntyre et al. 2009). Whilst community-ecosystem dynamics does recognise this, Massy (2013) believed it should be separately represented. Therefore human-social processes constitute a fifth category
Consequence of industrial-productivist agriculture on landscape processes

The soil-mineral cycle is degraded by poor farming practices (Oldeman et al. 1991). These include overgrazing, overcultivation, overuse of water, compaction from heavy machinery and the killing of beneficial organisms (Horrigan et al. 2002). The unsustainable use of soil in this way can result in desertification and the subsequent loss of arable land (Horrigan et al. 2002; Oldeman et al. 1991; Wood et al. 2000). Agricultural expansion also indirectly contributes to such losses, particularly when involving deforestation (Horrigan et al. 2002). Such ecosystem modification, land clearing and the consequential loss of carbon sinks directly contributes to climate change (Campbell et al. 2017; Houghton 2018)

The water cycle is degraded through the unsustainable overuse of fresh water (Gleick 2003; Postel 1996; Campbell et al. 2017) and the nutrient contamination of waterways; e.g. nitrogen, chemicals, silt, animal waste (Campbell et al. 2017; Horrigan et al. 2002). Agriculture is the largest global consumer of freshwater (Campbell et al. 2017). Humaninduced changes to the nitrogen cycle have had implications for water flows (Campbell et al. 2017; Moffat 1998). These include biodiversity loss and pollution as nitrogen is carried through the atmosphere, soils, marine waters and watersheds (Swaney et al. 2012; Howarth et al. 2011)

Community-ecosystem dynamics are degraded through the loss of biodiversity (Lindenmeyer 2007; Green et al. 2005; WRI 2005; Pimm and Raven 2000; Fowler and Mooney 1990; Rockstrom et al. 2009a, 2009b; Foley et al. 2005), specifically functional and genetic diversity (Steffen et al. 2015; Campbell et al. 2017). The development of protected areas is not preventing biodiversity loss (Pimm et al. 2014; Watson et al. 2010). Degradation also occurs due to monocultures, the conversion of land for agriculture (Horrigan et al. 2002), and the contamination of waterways-particularly nitrogen runoff (Horrigan et al. 2002; Moffat 1998; Campbell et al. 2017). Climate change and habitat fragmentation are facilitating the spread of invasive species, which also contributes to ecosystem degradation (Thomas et al. 2004; Campbell et al. 2017)

Solar-energy flow is degraded through increasing energy consumption (Foley et al. 2005) and unsustainable energy use (Pimentel and Pimenel 1996). This contributes to climate change (Campbell et al. 2017). It includes the extractive and unsustainable use of past solar energy (fossil fuels) for production, processing, transport, retail and waste (Campbell et al. 2017; Horrigan et al. 2002). The conversion of grain into meat (particularly using cattle) results in large losses of food energy (Horrigan et al. 2002). The photosynthetic capacities of farming ecosystems are often hampered by poor crop, pasture and livestock management (Massy 2013, 2017). In particular, overcultivation and overgrazing (Horrigan et al. 2002). These can create low plant density (Savory and Butterfield 2016) and desertification (Horrigan et al. 2002). This means less energy can be converted from sunlight into edible forms (Savory and Butterfield 2016)

Degradation in the physical health of human beings can be linked to animal-based food (Horrigan et al. 2002; DHHS 1988; Massy 2013); pesticide, chemical and fertiliser use (DHHS 1988; Horrigan et al. 2002; Albrecht 1975 (2005); Brussaard et al. 2007; Massy 2013); malnutrition (De Onis et al. 1993) and overnutrition (Horrigan et al. 2002); as well as factory pollution and food-borne pathogens (Horrigan et al. 2002; DHHS 1988; Massy 2013). The mental and physical wellbeing of farmers is threatened by environmental and community change or crisis (Ellis and Albrecht 2017; Albrecht 2007; Perceval et al. 2018a, 2018b); isolation; animal suffering; and the unavailability of services (Perceval et al. 2018a) 
Table 2 Reigning and alternative ideas in agriculture. Adapted from Massy (2013, pp. 182-184)

\begin{tabular}{|c|c|}
\hline Reigning industrial-productivist ideas in agriculture & Alternative ideas in regenerative agriculture \\
\hline $\begin{array}{l}\text { Man dominates nature: “...that 'man' can dominate and control nature } \\
\text { which is not revered” }\end{array}$ & $\begin{array}{l}\text { Collaborate with ecological systems: an agriculture that respects, } \\
\text { animates and works with ecological systems }\end{array}$ \\
\hline $\begin{array}{l}\text { Agrarianism: “.... a mal-adapted agricultural approach to the ... environ- } \\
\text { ment" }\end{array}$ & $\begin{array}{l}\text { Regenerate: a co-evolved approach that regenerates the diversity, resil- } \\
\text { ience and health of the environment }\end{array}$ \\
\hline $\begin{array}{l}\text { Economic utilitarianism-rationalism: “.... an implicit belief ... in land- } \\
\text { use decisions being based on narrow economic criteria" }\end{array}$ & $\begin{array}{l}\text { Landscape health: a belief in basing decisions on diverse, interrelated } \\
\text { phenomena; including overall landscape health }\end{array}$ \\
\hline $\begin{array}{l}\text { Science and technology rules: “.... powerful faith in technology and } \\
\text { industrial science which holds that 'man' can know everything in } \\
\text { order to dominate and control nature, thereby further separating 'man' } \\
\text { from nature" }\end{array}$ & $\begin{array}{l}\text { Holism: a transdisciplinary approach that is comfortable in ambigu- } \\
\text { ity-not everything can be known or controlled; all phenomena is } \\
\text { unbelievably complex and part of an interrelated whole }\end{array}$ \\
\hline $\begin{array}{l}\text { Aggressive language: language is “....reductionist, masculine, aggres- } \\
\text { sive, mechanistic, technical, quantitative, prescriptive, extractive, } \\
\text { humanistic and interventionist” (Massy 2013, p. 194) }\end{array}$ & $\begin{array}{l}\text { Nurturing language: language is “....feminine, cooperative, collabora- } \\
\text { tive ... giving ... nurturing, organic, sympathetic, loving, non- } \\
\text { mechanical ... holistic ... less reductionist, less humanistic ... less } \\
\text { egotistically focussed, less interventionist ... more passive ... less } \\
\text { technocratic" (Massy } 2013 \text {, p. 194) }\end{array}$ \\
\hline $\begin{array}{l}\text { Control metaphors: 'conquering nature,' 'nature as machine' and 'God } \\
\text { as divine lawgiver,' whom bestowed upon humanity 'dominion over } \\
\text { nature' (Lent 2017). Even 'steward of nature' is a metaphor that rein- } \\
\text { forces ideas of control (Lent 2017) }\end{array}$ & $\begin{array}{l}\text { Mother metaphors: landscapes are more akin to the 'nurturing mother' } \\
\text { (Massy 2013). This aligns with early Indigenous metaphors, which } \\
\text { perceived 'mother nature' as the 'giving parent' (Lent 2017) }\end{array}$ \\
\hline
\end{tabular}

et al. 2021). Different aspects from alternative agricultural approaches are integrated into regenerative farming systems (Wahl 2016). For example, Taranaki Farm in Australia includes aspects of holistic management, keyline farming and permaculture (Duncan and Savory 2015; Duncan 2015). This is because regenerative agriculture, "does not preclude any particular practice if it is needed to facilitate the transition of the agroecosystem to a state of increased health" (Grelet et al. 2021, p. 7). As such, rather than being prescriptive about using particular practices or processes, regenerative agriculture is generally outcomes focussed (Grelet et al. 2021). Some process-based definitions also exist (Newton et al. 2020); which are more inflexible with what constitutes 'regenerative.' These conflicting definitions demonstrate the lack of theoretical depth and consistency in regenerative agriculture.

The relevance of different agricultural practices to regenerative agriculture depends on the context of each farm (Grelet et al. 2021). Soloviev and Landua (2016, p. 4) suggest that, "each community of practitioners in each bioregion of the world has the opportunity to regenerate the eco-cultural meaning of regenerative agriculture. They will do so in a way that is unique to their place, history and whole living ecosystem." As such, whilst regenerative farmers around the world are managing landscapes in an integrated way (Scherr et al. 2012), context specifies which practices and philosophies are included.

Regenerative agriculture shares discursive elements with regenerative development: a practice that seeks to align human activities with the continuing evolution of living systems (Mang and Reed 2012; Benne and Mang 2015; Haggard and Mang 2016; Muller 2020; Plaut and
Amedee 2018). Regenerative development emerged in design and architecture (Svec et al. 2012; Plaut et al. 2012; Lyle 1994; France 2008; Dias 2015; Cole et al. 2012, 2013; Cole 2012a). Whilst not originally agricultural, it has influenced the approach of some farming communities, such as the consultancy Terra Genesis International (Soloviev and Landua 2016). This is an example of how regenerative agriculture is situated within a broader circle of discourses, which span multiple sectors (Wahl 2016). These discourses include urban design (Zari 2012, 2015; Gou and Xie 2017), regenerative economics (Fullerton 2015; Morseletto 2020), regenerative businesses (Sanford 2017, 2011), regenerative sustainability (Hes and du Plessis 2015; Gibbons 2020) and regenerative health (United 2020).

Regenerative has been conceptualised as the "new sustainable' (Gibbons 2020). However, for many practitioners, the concept carries greater ethical connotations, "to effect a complete moral reform" (Massy 2013, p. 23). Whilst sustainable systems must maintain the status quo and "their productivity and usefulness to society indefinitely" (Duesterhaus 1990, p. 22; Tilman et al. 2002), regenerative systems go a step further in restoring what has been lost and improving what is currently there (White 2020; Rhodes 2017, 2012; Schreefel et al. 2020). Participants of regenerative discourse believe that it is not enough to sustain dysfunctional approaches to landscape management (Gosnell et al. 2019). Despite this assertion, it remains unclear whether regenerative approaches can shift the discursive power of industrial-productivist agriculture. The clear ideological differences between these approaches (see Table 2) indicate that a shift to regenerative agriculture would indeed be transformative. However, just listing these differences 
tells us little about regenerative agriculture's transformative potential. Before turning to our methods for exploring the discursive characteristics and transformative potential of regenerative agriculture, the next section provides further detail on the conceptual framework for the paper.

\section{Discourse as a conceptual framework for agricultural transformations}

Discourses are, "a shared way of apprehending the world" (Dryzek 2013, p. 5). What is being shared is a complex network of meanings, phrases, practices and institutional structures that form a restrictive or expressive code of conduct. They tell a story about the way the world is, and our relationship to it, that influences our behaviour (Riedy 2020). As such, discourses can open us up, or close us down, to opportunities for transformation-depending on the storylines associated with them. The adoption of regenerative agriculture not only entails, "a new way of doing agriculture; but a new philosophy, a new worldview and a new ethicsvalues base," which will likely put farmers "at odds with peers, farming district and even family" (Massy 2013, p. 231). This is because regenerative discourses inhabit a different set of storylines to industrial-productivist agriculture.

Dryzek (2013) introduces four elements of discourse: agents and their motives; basic entities whose existence is recognised or constructed; assumptions about natural relationships; metaphors and other rhetorical devices. One such rhetorical device is the use of shared storylines that bind participants together in discourse coalitions (Hajer 1995). These elements of discourse are mobile-ideas, metaphors or storylines move from mind to mind within and across discourses. For example, unquestioned agricultural practices and assumptions that influence how we perceive, relate and think about landscapes can persist across discourses. In this paper, we identified key themes within regenerative agricultural discourses.

A theme is an, "extended phrase or sentence that identifies what a unit of data is about and/or what it means" (Saldana 2009, p. 199). It is helpful in revealing the, "psychological world of beliefs, constructs, identity development and emotional experiences" (Saldana 2009, p. 200). Whilst we considered themes at the semantic level-in the content of what was being said (Braun and Clarke 2006), we principally searched for themes at the latent level (Saldana 2009). The latent level considers the form used to express insights (Braun and Clarke 2006). For example, a farmer discussing resilience may say that nature is able to laugh or shrug things off or that native grasses don't mind being eaten off (Massy 2013). At the semantic level these comments can be taken at face value-the landscape is resilient. However, the farmer's metaphor use suggests that themes at the latent level may include a belief in ecological agency or animacy. In discussing transformative opportunities, we explored common ground and tension between the themes of regenerative discourses identified in this paper.

In discussing the transformative opportunities of regenerative discourses, we looked for common ground across our themes because a discourse is by definition shared. As such, common ground in this paper reflects the clear, united strengths shared within and between discourses. These are points of connection, where allies might rally around shared storylines. We also looked at areas of tension within the themes, because this can indicate how the discourse might be changing. Tensions demonstrate either uncertainty or differences within and between discourses. They can also provide creative points of productive, agonistic dialogue and mutual learning.

Common ground and tension offer insight into leveraging regenerative discourses for transformation. The transformative opportunities discussed in this paper are 'deep' leverage points; as explored by Abson et al. (2017) and Tourangeau and Sherren (2020), based on the foundational work of Meadows (2008). This is because discourses include the goals, norms, values and narratives of a system; existing in its ontological and epistemological realms (Davila et al. 2021). They are the, "individual and collective ideas ... which are in turn inherited, formed, transformed, negotiated or fought for" (Obrien 2018, p. 157). Points of common ground and tension have strong leverage potential because if common ground shifts, the whole discourse shifts. Likewise, tensions can either trigger shifts or cause new discourses to splinter off. Identifying how points of common ground and tension might be leveraged is one way of exploring whether regenerative agriculture offers opportunities to transform industrial-productivist agriculture.

\section{Methods}

The main method used in this paper was a literature-based discourse analysis. There have been systematic reviews of regenerative agriculture (Newton et al. 2020; Schreefel et al. 2020); which focussed on definitions. Our literature review complements these existing reviews, as we apply a discursive lens to regenerative agriculture. We did not seek to define regenerative agriculture, but rather to identify discursive characteristics and transformative opportunities. This advances the conceptual clarity of the discourses and their transformative potential.

The initial literature was sourced from agricultural practitioners through the recommendations of farmer networks in Australia, specifically, the Regenerative Agriculture Alliance and Institute of Ecological Agriculture. This was a starting point for the review. We wanted to understand what 
regenerative farmers saw as the key texts underpinning their discourse. The goal was to include the texts farmers actually use in their practice. Their recommendations included a diverse range of historical and grey literature, which act as the theoretical and philosophical foundation for many regenerative farmers.

Recognising the potentially eclectic nature of the recommended literature, we supplemented it with a systematic search of recent literature. Regenerative agriculture has radically increased in popularity, hype and ideology within the last 5 years (Stuart and Clemens 2018). It was important that relevant items had not been overlooked from that period, from 2016 to 2020. As such, a search in Google Scholar was conducted for academic articles with 'regenerative agriculture' in the title, published between 2016 and 2020. 59 items were identified in the Google Scholar search. We recognise that Google Scholar ranks search results in priority order, using an algorithm that is unknown but appears to make heavy use of citation counts and words in the title. It also doubled up on papers occasionally or was missing references. Given these limitations, we augmented Google Scholar with an additional search using Web of Science. We used the same search criteria in both searches; Web of Science returned 16 items. Of these four were missing from our literature collection, as such we subsequently included them in the review (Francis 2016; Hartle 2016; Sayre 2019; McDonald 2017).

Finally, we explored the citations in papers and used the 'cited by' function in Google Scholar and Web of Science to find further related articles on regenerative agriculture. 97 texts were identified this way. Three papers that were not included were also suggested by anonymous reviewers (Tourangeau and Sherren 2020; Tourangeau et al. 2019; Gosnell et al. 2020a). After identifying texts from these sources, 267 items were included in the review overall-104 from farmer networks, 59 from Google Scholar, 4 from Web of Science, 97 from citations and three from reviewer suggestions.

Analysis was undertaken iteratively as the body of literature expanded. Our research question asked: what are the discursive characteristics of regenerative agriculture? We were aware that such a question would shape the kind of knowledge we generated (Saldana 2009), so kept it front of mind throughout the analysis. We gathered information about the context that shaped the literature. This was recorded in analytic memos throughout the analysis period. These included insights from interactions with farmers who had suggested texts. This helped us document the context and its influence on the discourse. Before texts were analysed, we read and annotated them actively, which further informed analytic memos. Whilst annotating, we paid close attention to how rhetoric was being employed to put down any oppositional arguments or elicit a particular response from readers. This was a way of validating whether regenerative discourses were a departure from industrial-productivist agriculture.

Because the aim of the research question was to characterise the discourses, we predominantly looked for similarities and contrasts across texts. To achieve this, we drew on themeing the data in Saldana (2009). As mentioned, we principally identified themes at the latent level (Saldana 2009). This level better expresses phenomenological insights of the life-world; what it is like to be, have and live (Saldana 2009). As such, this approach better suited our research question. Themes were reviewed by:

- Comparing them with the original data extracts to ascertain whether integrity has been maintained throughout the process.

- Considering whether themes made sense in the context of the broader data set. This involved re-reading the literature and adding additional data that might have been missed.

\section{Findings: what is regenerative agricultural discourse?}

This review identified six themes, which express the characteristics of regenerative agricultural discourses.

\section{Theme one: regenerative agricultural work is conducted within nested, complex living systems}

Regenerative farmers increasingly adhere to principles of resilience, design and systems thinking (Mann et al. 2019; Gosnell et al. 2019). They believe, "that a healthy, non-degraded or regenerating ecological system has a selforganising propensity which drives or inclines that system to greater complexity, greater interdependence, greater diversity and thus greater resilience" (Massy 2013, p. 252). As such, "regenerative agriculture is deeply rooted in enabling the expression of nature's capacity for self-organisation" (Massy 2013, p. 24). This concept can be linked with symmathesy, which occurs when a system internally and externally engages in context specific, mutual learning through ongoing interaction (Bateson 2015). The systems are complex, interrelated and exhibit emergent behaviour, which is hard to predict (Provenza et al. 2013). The novel patterns and properties that emerge (Goldstein 1999) are unpredictable because the identity and nature of the interactions are creative (Provenza 2008) and unknown.

There is general consensus that complex living systems and their interrelated, self-organising inclinations must be understood holistically (Savory and Butterfield 2016; Haggard and Mang 2016). The work of Smuts (1973) 
and Koestler (1967) have been foundational in shaping such approaches, particularly within holistic management (Savory and Butterfield 2016). However, not everyone considers holism to be a prerequisite for regenerative agriculture. This is reflected in the distinction identified by Gosnell et al. (2020a) between 'managed grazing' as described in Hawken (2017) and 'regenerative ranching.' Both of these are included in regenerative agriculture, however regenerative ranching is the only one that infuses managed grazing with holistic decision-making. As such, it cannot be presumed that managed grazing and holistic decision-making always co-exist in regenerative agriculture. Some authors avoid being associated with holism all together. Instead of holistic grazing or holistic management, they have deferred to terms like 'multipaddock adaptive grazing,' or 'adaptive management' (Hodbod et al. 2016; Teague and Kreuter 2020; Teague and Barnes 2017; Park et al. 2017; Becker et al. 2017). These differences are semantic, but in many cases regenerative farmers also have different applied understandings of holism. For example, the holistic decision-making framework steps back from the parts to see the whole (Savory and Butterfield 2016), whereas adherents to Goethe's approach go into the parts to see the whole (Bortoft 1996). There are also holarchic or nested approaches to holism (Wilber 2001; Haggard and Mang 2016; Benne and Mang 2015). These terms - holarchic and nested—are often used interchangeably, denoting that, "all living systems are made of smaller systems nested within larger systems ... all of these levels of systems are whole and distinct from one another, and at the same time, they are dynamically interdependent and inseparable" (Haggard and Mang 2016, p. 45). This gives self-organisation an expansive quality; as if overlapping, interrelated systems were interacting and evolving ever-outwards.

In simplifying production systems we have suppressed nature's capacity to self-manage, leading to less resilient landscapes (Haggard and Mang 2016; Provenza 2008). However, Australian farmer Colin Seis let ecological systems self-organise because he could no longer afford the rising costs associated with chemical inputs, pasture seed, increasing salinity, reducing fertility and dying trees (Hes and Rose 2019; Massy 2017). Initially, "the wheels fell off everything, and our production crashed for seven or eight years" (Massy 2017 , p. 196). Once Seis overcame this period and associated doubts, a natural grassland evolved. The farm began enjoying more biodiversity and sequestering higher rates of carbon, which improved the soil's water holding capacity, crop yields, available fodder and animal production. Many input costs were no longer necessary because the landscape was self-healing (Hes and Rose 2019; Massy 2017). He says, "the closer I work to nature ... the easier it becomes, and the more profitable it becomes, and there's less costs, a lot less risk, and certainly a lot less work" (Massy 2017, p. 202).
Seis also experienced a discursive shift; his thinking became more ecological and he developed a desire to continually evolve this through ongoing learning (Hes and Rose 2019; Massy 2017).

Gosnell et al. (2020a) point out the nested nature of systems, where farmers are constrained by interacting social and ecological variables. In order for agricultural landscapes to function regeneratively, farmers must understand the interrelated and nested systems within which they conduct their work-precisely because it is these systems that will begin to regenerate (Haggard and Mang 2016; Soloviev and Landua 2016). Such understanding is a prerequisite to managing the systems regeneratively, and both understanding and managing these systems can be challenging for someone transitioning from industrial-productivist agriculture (Gosnell et al. 2020a).

\section{Theme two: farms are relational; co-evolution occurs amongst humans and other landscape biota}

The self-organising and interacting nature of living systems supports the description of farming offered by Gosnell et al. (2019); that the farm is a process of becoming. They say, "becoming is an outcome of dynamic networks comprised of heterogeneous relationships and actors existing and exerting agency at multiple scales and across time" $(2019$, p. 5). In other words, regenerative farmers understand that their farm is relational. They are therefore in constant becoming, or co-evolution, with their farm system and structurally coupled with its ecology. Structural coupling refers to the local and recurrent interactions between organisms in an environment, which leads to their congruence (Maturana and Varela 1992, 1980; Maturana 2002; Capra and Luigi Luisi 2016). As interdependence increases between human and non-human organisms on the farm, co-evolution can happen at multiple levels across cultural and ecological systems. This might be through language, epigenetics, diet, behaviour and experience (Provenza 2008; Lipton 2005; Maturana and Varela 1992).

When farmers and their ecosystems are structurally coupled it is an enablement of what Mang and Reed (2012) term co-evolving mutualism - "the increasing and mutually beneficial integration of human and natural systems that supports their co-evolution" (Mang and Reed 2012, p. 34). They refer to this as a process of progressive harmonisation. Many regenerative farmers animate nature as a nurturing mother (Massy 2013). This suggests a newfound intimacy and trust that would progressively harmonise the recurrent interactions between them. The mother that biologically births and sustains you is treated differently from an industrial commodity. Such relationality is a reminder that, "we too are ancient animals who co-evolved in landscapes and became genetically and physiologically hard-wired for 
dynamic biogeochemical interaction with these landscapes" (Massy 2017, p. 311). Regenerative agriculture requires never-ending creative interactions with other lifeforms (Provenza et al. 2013) and a constant co-evolution in land and thinking (Soloviev and Landua 2016). This is because the unique places we inhabit are dynamically interacting with us (Provenza 2008).

\section{Theme three: the innate potential of living systems is place-sourced}

A key premise of regenerative development is that, "coevolution among humans and natural systems can only be undertaken in specific places, using approaches that are precisely fitted to them" (Haggard and Mang 2016, p. 36). The concept of place represents the ecological and cultural context from which higher levels of order can emerge. Mang and Reed define it as, "the unique, multi-layered network of living systems within a geographic region that results from the complex interactions, through time, of the natural ecology ... and culture" (2012, p. 28). Regenerative farmers develop a deepened pattern understanding of their place (Drengson 1985; Mollison 1988), and subsequently the place essence associated with those patterns (Soloviev and Landua 2016).

Essence can be understood as, "the true nature or distinct character that makes something what it is; the permanent versus the accidental element of being" (Haggard and Mang 2016, p. 48). Discerning the essence of a place begins with recognising, "that each place is a dynamic entity with its own unique history and future - growing and evolving, forming and decomposing, continuously influenced by the larger system in which it is embedded" (Mang and Reed 2012, p. 31). Based on their unique essence, places have "an inherent potential to which they are moving toward or away, depending on their state of integrity and vitality" (Mang and Reed 2012, p. 30). This potential defines the vocation of that place. It is the place's capacity for adding value to the broader ecological and cultural whole within which it is nested (Mang and Reed 2012).

Haggard and Mang (2016) provide a good example of this theme. The National Park Service wished to restore a 100-acre farm that had supplied produce to the historic Hubbell Trading Post in the Navajo Nation at Ganado, Arizona. To make Hubble Farm economically viable, they suggested leasing it to produce alfalfa hay. However, the alfalfa hay did not express what was unique about Hubble Farm, nor its potential for creating new value for the larger whole within which it was nested. At that time, locals wanted to promote traditional crops, the hospital was running an anti-diabetes project and the high school was reviving threatened Churro sheep. These groups came together and managed the farm collaboratively. It provided pasture for the sheep, native crops for the diabetes program, hedgerows were created for traditional plants and the sheep provided high-quality wool and lamb. For farmers, working regeneratively requires considering the unique essence and potential of the living systems that form their place (Soloviev and Landua 2016). This often involves participation in reconciliation initiatives that address the trauma experienced by places and their Indigenous people, at the hands of settler colonialism (Brewer 2019).

\section{Theme four: openness to alternative thinking and practice is transformative}

The first principle of regenerative food systems as identified by Duncan et al. (2020, p. 5) is to, "acknowledge and include diverse forms of knowing and being in the world." Regenerative farmers demonstrate a radical evolution in thinking with their willingness to learn and openness to alternative ideas or practice (Gosnell et al. 2019). Like Seis, many have proclaimed that the transformation they experienced left them addicted to ongoing learning (Hes and Rose 2019; Massy 2017). This means constantly questioning their assumptions, beliefs and feelings in order to let their own complex, psychological systems self-organise in sync with structurally coupled landscapes (Massy 2013). In this sense it has freed them from cultural norms and patterns constraining the potential for self-actualisation (Boyd 1991) in themselves and their farm ecosystems. This theme builds intuitively on the findings of Gosnell et al. (2019); that ongoing learning, enthusiasm and positive feedback associated with ecological monitoring leads to greater regenerative potential and higher levels of awareness over time. They demonstrate how certain activities, experiences or perceptions can, "support selfamplifying feedback loops that involve ongoing experiential social learning and increasing consciousness which plays out on the landscape and in surrounding communities" (Gosnell et al. 2019, p. 11). As such, a sense of constant discovery is enticed, which leaves regenerative farmers indefinitely open to transformation.

Accepting different ways of knowing that are potentially contradictory to previous experience is a quality that Massy (2013) associates with transdisciplinary inquiry. This involves a level of synthesis within an individual that helps them better empathise with the thought processes of others, that is absent in traditional disciplinary thinking (Max-Neef 2005). Such thinking draws from but transcends disciplinary boundaries and paradigms (Bernstein 2015; Gibbs and Beavis 2020; Nicolescu 2002). Massy (2013) believes regenerative farmers demonstrate such an approach and form their own integrated knowledge cultures by questioning dominant assumptions and forms of knowledge that marginalise other ways of knowing. This adheres to the transdisciplinary discourse of transgression (Klein 2015) and aligns with the 
non-prescriptive features of regenerative agriculture (Grelet et al. 2021).

For some, this openness makes attempts to 'define' the concept and practice of 'regenerative' agriculture counterintuitive (Newton et al. 2020). The two words have opposite meanings, with the Latin origins of the former denoting, "bring to an end" (Soloviev and Landua 2016). There is a reluctance to define regenerative agriculture because it is perceived as something that should continually evolve with the ongoing learning of farmers (Newton et al. 2020). The definition itself needs to constantly be regenerated (Soloviev and Landua 2016). Further, definitions tend to create boundaries and exclude minority interpretations; whereas regenerative agriculture is generally inclusive of diverse forms of knowing and being (Duncan et al. 2020). As such, some in the movement are, "understandably averse to adopting a single definition for strategic, political, or conceptual reasons as their thinking on this relatively new topic continues to evolve" (Newton et al. 2020, p. 6). It has been suggested that individuals and organisations have an understanding specific to their own context and purpose (Newton et al. 2020), which can freely evolve through engagement with other practitioners.

\section{Theme five: multiple regenerative cultures are necessary for deeply regenerative agriculture}

While there are important exceptions (Hintz 2015b, 2015a; Kearnes and Rickards 2020; Sherren and Kent 2017; Mann and Sherren 2018; Mann et al. 2019), most descriptions of regenerative agriculture do not focus on the "mental/social aspects of people working on the land" (Hes and Rose 2019, p. 10). This is demonstrated in Newton et al. (2020). Only $17.4 \%$ of their reviewed journal articles (121) and $40.9 \%$ of their reviewed practitioner websites (22) mention improving the "social and/or economic wellbeing of communities" when defining or describing regenerative agriculture (Newton et al. 2020, p. 5). Another example is the description by California State University (CSU) Chico (2017), which identifies benefits to soil, water, biodiversity and carbon; but not people. Silence on regenerative agriculture's social dimension is replicated in many articles (Elevitch et al. 2018; LaCanne and Lundgren 2018; Lal 2020; Quarles 2018; Colley et al. 2019; Gopal et al. 2020; Soto et al. 2020). However, the important role of human-social processes is increasingly recognised and discussed. For example, the work of Gosnell et al. (2020b) explores multiple facets of holistic management, which span the human-social rather than just the biophysical. Massy $(2013,2017)$ goes into substantial socio-cultural depth, actually coining the term 'human-social' in the context of the Savory and Butterfield (2016) landscape processes. For many practitioners, regenerative agriculture is not simply a new suite of climate smart tools but a dynamic and discourse-shifting approach to landscapes that re-embeds their cultural significance (Cross 2013; Gosnell et al. 2019).

Soloviev and Landua (2016, p. 13) remark that, "deeply regenerative agriculture can exist only if it is completely interwoven into a thriving regenerative culture." On an individual level, farmers are developing their own regenerative farm cultures. This comes through in their communities of practice (Cross and Ampt 2017), holistic-complex systems thinking (Massy 2017), changed financial planning (Gosnell et al. 2020b), ongoing learning (Gosnell et al. 2019) and openness to diverse ways of knowing and being in landscapes (Duncan et al. 2020). However, more industrial-productivist discourses still permeate outside the farm and its associated regenerative community (Lawrence et al. 2013). As such, regenerative agriculture operates within nested systems of other dominating discourses, which influence its capacity to function regeneratively. For example, a regenerative farm will still suffer the consequences of humaninduced climate change. As such, regenerative agriculture works to its fullest capacity if the economic, political and social systems within which it is nested, are also regenerative (Soloviev and Landua 2016; Wahl 2016).

This is why it has been suggested that regenerative agriculture needs to remain connected with broader regenerative movements, such as regenerative development (Hes and Rose 2019). Soloviev and Landua (2016, p. 14) comment that, "agriculture becomes a central set of annual rituals and ceremonies that is integral to the ongoing regeneration of culture." Wahl (2016) asserts that regenerative cultures can be designed from the overlapping cultural and ecological systems of individual bioregions. Hence, there is not a single regenerative culture, but numerous depending on the uniqueness of different places. Regenerative agriculture would similarly express itself differently depending on the cultural and ecological systems of its place (Grelet et al. 2021).

\section{Theme six: regenerative approaches depart from industrialism to varying degrees}

Industrialism, and all of the ideologies that have been associated with it, ignored and suppressed the environment (Dryzek 2013). As Dryzek suggests, "if what we now call environmental issues were thought of at all, it was generally in terms of inputs to industrial processes" (2013, p. 14). Hence, like all environmental discourses, regenerative discourses are departures from industrialism, but the degree of departure can vary. This allows regenerative agriculture to be championed by what many consider opposing sides of the food and agriculture debate-NGO's and civil society, as well as major multi-national companies (Giller et al. 2021).

Companies such as General Mills, Patagonia and Cargill have developed regenerative agriculture programs that 
Table 3 Key themes of regenerative agricultural discourses

\begin{tabular}{|c|c|c|}
\hline \# & Theme & Explanation \\
\hline 1 & $\begin{array}{l}\text { Regenerative agricultural work is conducted within nested, complex } \\
\text { living systems }\end{array}$ & $\begin{array}{l}\text { Farms are nested within socio-ecological systems that self-organise } \\
\text { and interact unpredictably across scales. Farmers need to under- } \\
\text { stand how these systems function in order to manage them regen- } \\
\text { eratively }\end{array}$ \\
\hline 2 & $\begin{array}{l}\text { Farms are relational; co-evolution occurs amongst humans and other } \\
\text { landscape biota }\end{array}$ & $\begin{array}{l}\text { Regenerative agriculture requires never-ending creative interactions } \\
\text { with other lifeforms because the unique places farmers inhabit are } \\
\text { dynamically interacting with them }\end{array}$ \\
\hline 3 & The innate potential of living systems is place-sourced & $\begin{array}{l}\text { Places have a unique essence and inherent potential to which they are } \\
\text { moving toward or away. This informs a farmer's capacity for adding } \\
\text { value to the broader socio-ecological whole }\end{array}$ \\
\hline 4 & Openness to alternative thinking and practice is transformative & $\begin{array}{l}\text { Farmers need to question their assumptions, beliefs and feelings to } \\
\text { allow for transformative, self-actualisation in themselves and their } \\
\text { farm ecosystems }\end{array}$ \\
\hline 5 & $\begin{array}{l}\text { Multiple regenerative cultures are necessary for deeply regenerative } \\
\text { agriculture }\end{array}$ & $\begin{array}{l}\text { A plurality of regenerative cultures can emerge from the socio- } \\
\text { ecological systems of different bioregions. Deeply regenerative } \\
\text { agriculture requires the socio-economic systems within which it is } \\
\text { nested to also be regenerative }\end{array}$ \\
\hline 6 & $\begin{array}{l}\text { Regenerative approaches depart from industrialism to varying } \\
\text { degrees }\end{array}$ & $\begin{array}{l}\text { Regenerative agriculture departs from industrialism to varying } \\
\text { degrees and thus includes diverse ways of 'doing' agriculture }\end{array}$ \\
\hline
\end{tabular}

nevertheless maintain productivist thinking. Cargill has 155,000 employees operating across 70 countries, moving countless products around the world via roads, rail, rivers and oceans (Cargill 2020a). They aim to, "advance regenerative agriculture practices across 10 million acres" (Cargill 2020b) and "build long-term economic viability" (Cargill 2020c). This maintains the industrial-globalised landscape but partners it with 'regenerative practices.' Nevertheless, the language of these organisations explicitly critiques industrial-productivist approaches. Patagonia says on their website, "growing food and fibre with industrial techniques has devastated our climate" and that "big agriculture is broken" (Patagonia 2020). General Mills even identifies the need for transformative change (Mills 2020). This departure may only be semantic, but it still disassociates them from extractive agricultural narratives.

These companies have been criticised for confusing regenerative principles with basic practices that do not require a shift away from industrial-productivist thinking (Gordon 2021). General Mills lists six principles that are all practice based; for example, "reduce soil disturbance," and "integrate livestock" (Mills 2020). By contrast, other widely supported regenerative principles focus on the way farmers think, as noted above. For example, "have the capacity for continuous, transformative learning" (Gordon 2021, p. 5), "make context-specific decisions" (Grelet et al. 2021, p. 15), or "express the unique and irreplaceable essence of each person, farm and place" (Soloviev and Landua 2016, p. 19). These tensions exist because each group advocating regenerative agriculture has departed from industrialism to varying degrees.
Increasingly, regenerative groups are First Nations led; such as the Regenerative Songlines Australia Network (Poelina et al. 2021). These perspectives reflect the most significant departure (Pascoe 2014; Gammage 2011; Murphy 2007; Salmon 2020, 2000; Sutton and Walshe 2021). Whilst it has been recognised that cultural (Angarova et al. 2020) and ecological (Graham and Bartel 2017) reconciliation is necessary for deeply regenerative agriculture, not everyone acknowledges this. As such, regenerative agriculture has been criticised for borrowing practices from Indigenous cultures, whilst leaving out their worldviews and hence erasing their history and contributions (Angarova et al. 2020; Romero-Briones et al. 2020). As Romero-Briones et al. (2020, p. 9) suggest, "both systems should be acknowledged and can work together," but the differences in how they know and explain the world should be recognised.

The above findings are summarised in Table 3 . In the next section, we discuss points of common ground and tension between the six themes. These provide insight into how transformative opportunities within regenerative discourses might be leveraged. Such leveraging can help shift the industrial-productivist discourse currently dominating agricultural mindscapes.

\section{Discussion: leveraging the transformative potential of regenerative discourses}

The six themes provide insight into whether regenerative discourses have the potential to transform industrial-productivist agriculture. Three opportunities for transformation 


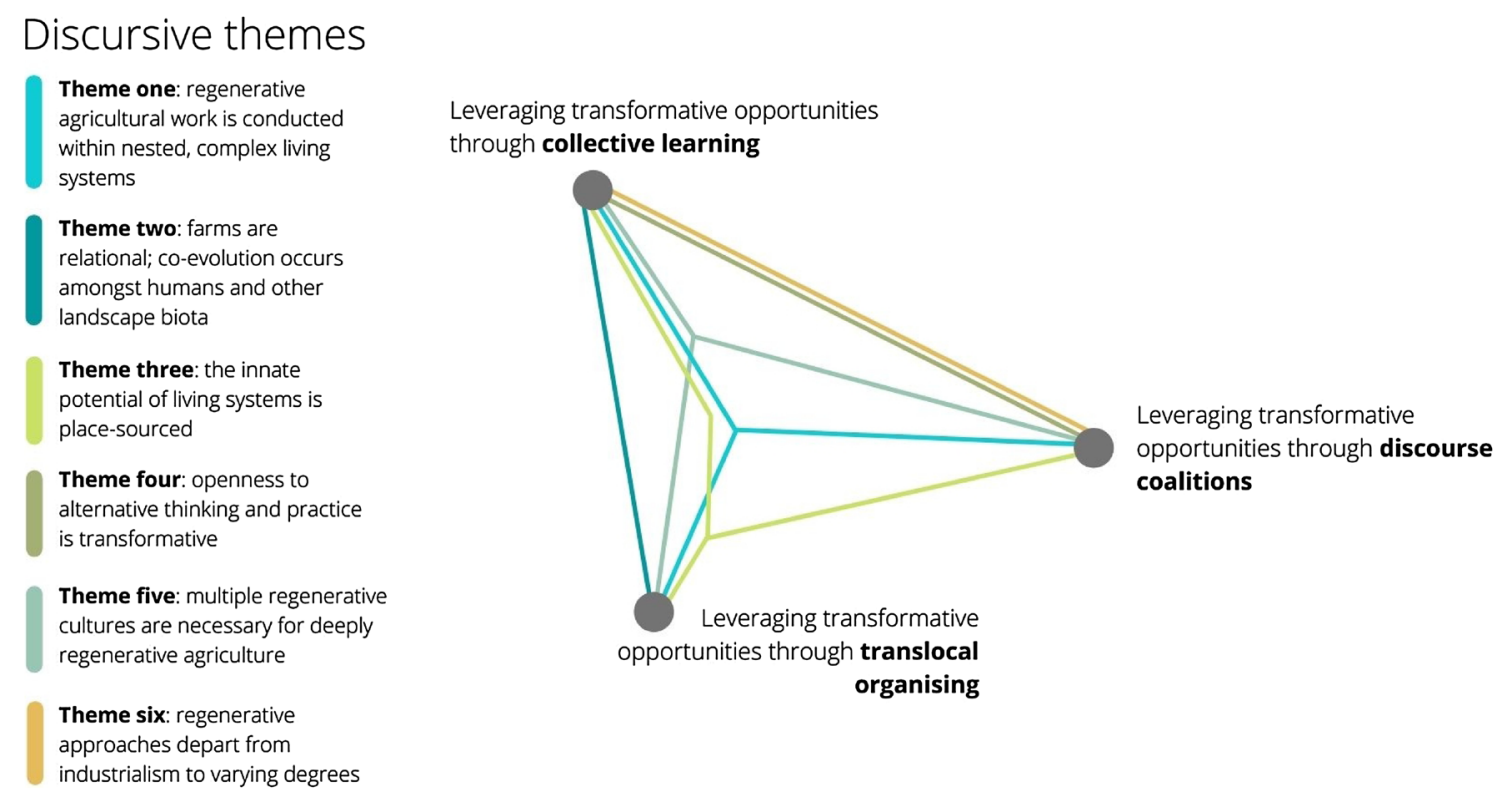

Fig. 1 Leveraging regenerative discourses for transformation

have been identified that reflect common ground and tension within these themes. Figure 1 visualises how these opportunities relate to the six themes as per our conceptual framework.

\section{Leveraging transformative opportunities through discourse coalitions}

Both theme four and previous studies demonstrate that regenerative agriculture often includes ongoing reflection and learning in relation to practice (Gosnell et al. 2019; Massy 2013, 2017). This involves being open to, and including, alternative views; whilst nevertheless holding fast to personal ecological vision. The focus on landscape and community potential in theme three also speaks to this openness as does the pluralism of theme five. In being open, inclusive and potential-oriented regenerative agriculture displays much common ground. It also creates room for numerous tensions, which demonstrate how regenerative agriculture is unsettled and contested.

The themes reflect variations in how regenerative agriculture is understood, practiced and discussed. For example, the nuanced differences to holistic thinking reflect variations in theme one as does the emphasis on, or exclusion of, human-social processes by some regenerative practitioners in theme five. Themes three and five demonstrate how regenerative agriculture can manifest differently across socio-ecological contexts. This includes differences in how it relates to bioregionally specific regenerative cultures. In theme four, if definitions remain vague in an attempt to be inclusive, regenerative agriculture could be co-opted by industrial-productivist agendas (Newton et al. 2020). However, if definitions are too restrictive they could exclude key allies in shifting industrial-productivist approaches. That no agricultural practice is necessarily precluded raises tensions between different departures in theme six-particularly when industrial practices are used, e.g. chemical inputs (Flynn 2020), or Indigenous practices are de-contextualised (Angarova et al. 2020). These tensions position regenerative agriculture well for discourse coalitions. Such alliances naturally create space for diverse interpretations to be included.

A discourse coalition consists of diverse agents collectively drawn to certain storylines; who then reproduce those storylines (Riedy 2020). In this case, agricultural alternatives increasingly find resonance with the umbrella or boundary narrative of regenerative agriculture. Meanwhile, their agricultural practice can include any activity focussed, "on enhancing and restoring holistic, regenerative, resilient systems supported by functional ecosystem processes and healthy, organic soils" (Gosnell et al. 2019, p. 4). As such, there is enough common ground in regenerative agriculture to feel included in the community, but also enough space for interpreting it in your own way. Thus, regenerative agriculture constitutes a boundary community that is integrative of multiple agricultural discourses. If those who seek more transformative departures from industrialism can strengthen their discourse coalition around regenerative agriculture, rather than abandon the term; then they might re-empower alternatives to industrial-productivist agriculture. 


\section{Leveraging transformative opportunities through translocal organising}

Themes one, two, three and five suggest the discourses co-evolve with specific localities and integrate relevant approaches (Grelet et al. 2021). The Savory Institute applies the same paradigms, principles, decision-making framework and testing questions to diverse locations or 'hubs' all over the world (Savory 2020). This reflects some uniformity by contrast; however the specific decisions that subsequently emerge still depend on local contexts. The place-based nature of regenerative agriculture could limit its transformative potential because each particular community will be place-bound and unable to share lessons with a wider (national or international) network. While recognising that any expression of regenerative agriculture must be local and context-dependent, the potential for transformation will grow if each regenerative community can find enough common ground to band together in translocal networks (Loorbach et al. 2020), expanding their power.

For example, in some cases agricultural transformation has been successful thanks to communities of practice that are not place-based (Cross and Ampt 2017). Whilst hubs (such as those initiated by the Savory Institute) that promote, disseminate and offer trainings in regenerative agriculture have emerged; these were not established and available to the early innovators. In fact, early agricultural innovators were ridiculed by local communities (Massy 2017). This ridicule remains a tension for the transformative potential of regenerative agriculture. It therefore makes sense that early innovators found common ground by organising and connecting across geographies. Ironically, this ability was made possible by an industrial-globalised agricultural landscape.

If regenerative agriculture is widely adopted, "it could be argued that communities of practice are also communities of place: adapting to local circumstances, using local resources, and feeding local people" (Cross and Ampt 2017, p. 596). In the meantime, transformative organising will still need to share characteristics with both place-based and industrial-globalised approaches (Cross and Ampt 2017). Hence becoming translocal and providing communities with diverse opportunities for common ground; particularly with increasing technological resources and literacy.

\section{Leveraging transformative opportunities through collective learning}

Gosnell et al. (2019) and Massy (2013) demonstrate that farmers have transformative experiences in their individual departures from industrial-productivist agriculture. This is also documented by farmers themselves (Anderson 2019; Brown 2018; White 2008) and reflected in themes one, two and four. Since regenerative agriculturalists have been through a transformative learning process, they are wellplaced to share their experiences and help others learn.

To be transformative, regenerative discourse-or discourse coalitions - can't just focus on their own regenerative practice (or the different departures in theme six). They need to engage in outreach and advocacy that influences oppositional discourses. Dryzek (2013, p. 234) suggests discourses are needed that, "facilitate and engage in collective learning in an ecological context." If regenerative approaches are to successfully transform industrial-productivist agriculture, they will need to constructively engage with those who have oppositional beliefs. This is not to say that oppositional discourses are encouraged, but they are nevertheless worked with. This particularly includes 'conventional' farmers who are threatened and annoyed by the "holier than thou philosophy" (Henly 2021, p. 77) of regenerative agriculture.

As implied by themes three and four, regenerative agriculturalists must continue questioning their own assumptions, beliefs and feelings to remain open and focus on the collective potential of diverse discourses. This leverage point doesn't 'convert' farmers to regenerative agriculture. It is an opportunity to transcend paradigms (Meadows 2008) and facilitate a co-evolution between discourses. The shift occurring within the competing discourse will be semantically and practically different, but nevertheless transformative for the individuals involved. Change will not be experienced in every situation, but continually trying to bring in new perspectives is important for this transformative opportunity. This kind of pluralism is foundational to theme five and can be achieved through outreach. The effectiveness of outreach will depend on the kind of language that regenerative discourses use to tell their stories; "thinking differently requires speaking differently" (Lakoff 2014, p. xiii).

Everything people do and say is filtered by metaphorical building blocks (Lakoff and Johnson 2008). For example, "a healthy ecosystem is the 'engine' behind a regenerative farm; it 'charges' your soil and 'drives productivity.'" This does not articulate an ecosystem in the same way that regenerative discourses perceive it. Rather, it subconsciously reinforces the conceptualisation of an ecosystem that already exists in industrial-productivist agriculture. When speaking about regenerative agriculture, it seems logical to use familiar language. This comes laden with the pre-established ideas of the dominant discourse. As Lakoff says, "you should say what you believe using your language, not theirs" (2014, p. xiii). Regenerative agriculture cannot be understood differently if the language still frames it within the conceptual confines of industrial-productivist thinking. Metaphor awareness can help people recognise the influence of conceptual realities; and if desirable, rebuke them. This empowers individuals and organisations to opt-out of extractive narratives. 


\section{Conclusion}

Industrial-productivist agriculture has contributed to the simplification and degradation of human and ecological systems. As such, agricultural transformation is essential for creating more sustainable food systems. A prominent discursive alternative to industrial-productivist agriculture is regenerative agriculture. The purpose of this paper was to illustrate thematic characteristics of regenerative agricultural discourses and identify whether these offer opportunities for transforming industrial-productivist agriculture.

Six themes have been presented that illustrate regenerative agricultural discourses. Firstly, regenerative agricultural work is conducted within nested, complex living systems. Therefore, ecological systems are encouraged to self-organise towards greater complexity, interdependence, diversity and resilience. Secondly, farms are relational; co-evolution occurs amongst humans and other landscape biota. Farmers are constantly co-evolving with farm ecosystems. Thirdly, the innate potential of living systems is place-sourced. Places have unique socio-ecological qualities that can be integrated with farming systems. Fourthly, openness to alternative thinking and practice is transformative. Engaging with diverse forms of knowing and being ensures that mindscapes are also regenerating. Fifthly, multiple regenerative cultures are necessary for deeply regenerative agriculture. Regenerative agriculture works to its fullest capacity if the economic, political and social systems within which it is nested, are also regenerative. Finally, regenerative approaches depart from industrialism to varying degrees. Regenerative agriculture therefore includes diverse ways of 'doing' agriculture.

It remains unclear whether regenerative discourses can shift industrial-productivist agriculture. We contribute to filling this research gap with three transformative opportunities. Firstly, regenerative discourses can be leveraged for transformative potential by creating common ground through shared storylines. Regenerative agriculture represents a growing discourse coalition that could significantly disrupt industrial-productivist agriculture if strengthened. Secondly, leveraging can occur through translocal organising; ensuring that regenerative farmers are well connected and supported. Thirdly, leveraging can occur by facilitating collective learning in an ecological context, particularly with oppositional discourses. This includes sharing personal stories of transformation using intentional language that does not cognitively support industrial-productivist ideas.

The transformative potential of regenerative agricultural discourses has only been marginally explored in the literature. This paper creates a foundation for exploring regenerative agricultural transformations through the discourse lens. Future research can build on this review in a variety of ways; but two gaps in particular offer opportunities for deeper insight. Firstly, this was an initial discourse analysis identifying key thematic characteristics of regenerative agricultural discourses. A deeper discourse analysis could go beyond themes and illustrate the specific agricultural discourses connected with regenerative narratives. This should draw on empirical work with farmers in addition to grey and academic literature on agricultural systems and narratives. Secondly, this research has identified three transformative opportunities that could be further explored through action research. These create a theoretical foundation for working with farmer networks aiming to shift industrial-productivist systems. There is also a role for designing, testing and evaluating discursive interventions for transformation with industrial-productivist farmers.

In an anthropocentric world, where agriculture contributes to the degradation of planetary systems; these findings reflect the urgent need for shifting industrial-productivist discourses. As a possible alternative, regenerative agriculture offers some promising transformative opportunities. Regardless of whether these are realised, new agricultural landscapes and mindscapes are required that embody deeply restorative discourses.

Supplementary Information The online version supplementary material available at https://doi.org/10.1007/s10460-021-10276-0.

\section{References}

Abson, D., J. Fischer, J. Leventon, J. Newig, T. Schomerus, U. Vilsmaier, H. von Wehrden, et al. 2017. Leverage points for sustainability transformation. Ambio 46: 30-39.

Albrecht, G., G.M. Sartore, L. Connor, N. Higginbotham, S. Freeman, B. Kelly, H. Stain, A. Tonna, and G. Pollard. 2007. Solastalgia: The distress caused by environmental change. Australasian Psychiatry 15 (1): 95-98.

Albrecht, W.A. 1975 (2005). Soil fertility and animal health: The Albrecht Papers. Austin: Acres USA.

Altieri, M.A. 1995. Agroecology: The science of sustainable agriculture., 2 Aufl. Boulder: Westview Press.

Anderson, M., and M. Revera-Ferre. 2021. Food system narratives to end hunger: Extractive versus regenerative. Current Opinion in Environmental Sustainability 49: 18-25.

Anderson, S. 2019. One Size Fits None: A Darm girl's search for the promise of regenerative agriculture. Lincoln: University of Nebraska Press.

Angarova, G., T. Ruka, S. Mitambo, B. Guri, K. Frederick, R. Haslett-Marroquin, M. Nelson, N. Kelley, and K. Chayne. 2020. Whitewashed hope: A message from 10+ Indigenous leaders and organizations: Regenerative agriculture and permaculture offer narrow solutions to the climate crisis. https://www.cultu ralsurvival.org/news/whitewashed-hope-message-10-indigenousleaders-and-organizations. Accessed 11 July 2020.

Argent, N. 2002. From pillar to post? In search of the post-productivist countryside in Australia. Australian Geographer 33 (1): 97-114.

Bateson, N. 2015. Symmathesy-A word in progress: Proposing a new word that refers to living systems. In Paper presented at 
the proceedings of the 59th annual meeting of the International Society for the Systems Sciences, Berlin, Germany.

Baumber, A., G. Metternicht, R. Cross, L. Ruoso, A. Cowie, and C. Waters. 2019. Promoting co-benefits of carbon farming in Oceania: Applying and adapting approaches and metrics from existing market-based schemes. Ecosystem Services 39: 100982.

Baumber, A., C. Waters, R. Cross, G. Metternicht, and M. Simpson. 2020. Carbon farming for resilient rangelands: People, paddocks and policy. The Rangeland Journal. https://doi.org/10.1071/ RJ20034.

Becker, W., U. Kreuter, S. Atkinson, and R. Teague. 2017. Whole-ranch unit analysis of multipaddock grazing on rangeland sustainability in north central Texas. Rangeland Ecology and Management 70 (4): 448-455.

Bene, C. 2020. Resilience of local food systems and links to food security-A review of some important concepts in the context of COVID-19 and other shocks. Food Security 12: 805-822.

Benne, B., and P. Mang. 2015. Working regeneratively across scalesInsights from nature applied to the built environment. Journal of Cleaner Production 109: 42-52.

Bernstein, J. 2015. Transdisciplinarity: A review of its origins, development and current issues. Journal of Research Practice 11 (1): R1.

Bortoft, H. 1996. The wholeness of nature: Goethe's way toward a science of conscious participation in nature. Hudson: Lindisfarne Books.

Boyd, R. 1991. Personal transformations in small groups. New York: Routledge.

Braun, V., and V. Clarke. 2006. Using thematic analysis in psychology. Qualitative Research in Psychology 3 (2): 77-101.

Brewer, J. 2019. Guiding the emergence of humanity's future: Reflections on the pedagogy of bioregional regeneration. Nicoya Peninsula: Regenerative Communities Network.

Brown, G. 2018. Dirt to soil: One family's journey into regenerative agriculture. White River Junction: Chelsea Green Publishing.

Brussaard, L., P. Ruiter, and G. Brown. 2007. Soil biodiversity for agricultural sustainability. Agriculture, Ecosystems and Environment 121 (3): 233-244.

California State University (CSU) Chico. 2017. What is regenerative agriculture? Definitions. https://holisticmanagement.org/wpcontent/uploads/2017/02/Regen-Ag-Definition-2-23-17.pdf. Accessed 14 Oct 2019.

Campbell, B.M., D.J. Beare, E.M. Bennett, J.M. Hall-Spencer, J.S. Ingram, F. Jaramillo, R. Ortiz, N. Ramankutty, J.A. Sayer, and D. Shindell. 2017. Agriculture production as a major driver of the Earth system exceeding planetary boundaries. Ecology and Society 22 (4): 8. https://www.jstor.org/stable/26798991. Accessed 25 Feb 2020.

Capra, F., and P. Luigi Luisi. 2016. The systems view of life: A unifying vision. Cambridge: Cambridge University Press.

Cargill. 2020. 2020 Annual report: Nourishing the world. Minnetonka: Cargill.

Cargill. 2020b. Cargill to advance regenerative agriculture practices across 10 million acres of North American farmland by 2030. https://www.cargill.com/2020/cargill-to-advance-regenerativeagriculture-practices-across-10. Accessed 11 June 2020.

Cargill. 2020c. Regenerative agriculture. https://www.cargill.com/susta inability/regenerative-agriculture. Accessed 11 June 2020

Carson, R. 1962 (1972 repr.). Silent spring. Ringwood: Penguin.

Codur, A., and J. Watson. 2018. Climate smart or regenerative agriculture? Defining climate policies based on soil health. Tufts University: Global Development and Environment Institute.

Cole, R. 2012a. Regenerative design and development: Current theory and practice. Building Research and Information 40 (1): 1-6.

Cole, R. 2012b. Transitioning from green to regenerative design. Building Research and Information 40 (1): 39-53.
Cole, R., P. Busby, R. Guenther, L. Briney, A. Blaviesciunaite, and T. Alencar. 2012. A regenerative design framework: Setting new aspirations and initiating new discussions. Building Research and Information 40 (1): 95-111.

Cole, R., A. Oliver, and J. Robinson. 2013. Regenerative design, socioecological systems and co-evolution. Building Research and Information 41 (2): 237-247.

Colley, T., S. Olsen, M. Birkved, and M. Hauschild. 2019. Delta life cycle assessment of regenerative agriculture in a sheep farming system. Life Cycle and Sustainability 16 (2): 282-290.

Conway, G. 1985. Agroecosystem analysis. Agricultural Administration 20 (1): 31-55.

Conway, G. 1987. The properties of agroecosystems. Agricultural Systems 24 (2): 95-117.

Cross, R. 2013. Conversations with farmers: Agri-cultural practice change and the 'Eco-Innovator'. PhD Dissertation, University of New South Wales, Australia.

Cross, R., and P. Ampt. 2017. Exploring agroecological sustainability: Unearthing innovators and documenting a community of practice in southeast Australia. Society and Natural Resources 30 (5): $585-600$.

Crutzen, P. 2002. Geology of mankind: The Anthropocene. Nature 415: 23.

Crutzen, P. 2016. Geology of mankind. In Paul J. Crutzen: A pioneer on atmospheric chemistry and climate change in the Anthropocene, ed. P. Crutzen and H. Günter Brauch, 211-215. Cham: Springer.

Davila, F., R. Plant, and B. Jacobs. 2021. Biodiversity revisited through systems thinking. Environmental Conservation. https://doi.org/ 10.1017/S0376892920000508.

De Onis, M., C. Monteiro, J. Akré, and G. Clugston. 1993. The worldwide magnitude of protein-energy malnutrition: An overview from the WHO global database on child growth. Bulletin of World Health Organisation 71 (6): 703-712.

DHHS. 1988. The Surgeon General's Report on Nutrition and Health. Washington, DC: US Department of Health and Human Services, Public Health Services.

Dias, B. 2015. Beyond sustainability-Biophilic and regenerative design in architecture. European Scientific Journal 11 (9): 147-158.

Drengson, A. 1985. The two philosophies of agriculture: From industrial paradigms to natural patterns. The Trumpeter: Voices from the Canadian Ecophilosophy Network 3: 17-22.

Dryzek, J.S. 2013. The politics of the earth: Environmental discourses, 3 Aufl. Oxford: Oxford University Press.

Duesterhaus, R. 1990. The SWCS view: Sustainability's promise. Journal of Soil and Water Conservation 45 (1): 4.

Duncan, J., M. Carolan, and J. Wiskerke. 2020. Routledge handbook of sustainable and regenerative food systems. New York: Routledge.

Duncan, T. 2015. Case study: Taranaki Farm regenerative agriculture: Pathways to integrated ecological farming. In Land restoration: Reclaiming landscapes for a sustainable future, eds. I. Chabay, M. Frick, and J. Helgeson. ProQuest Ebook Central. Elsevier Science and Technology. https://ebookcentral.proquest.com.

Duncan, T., and A. Savory. 2015. Regenerating agriculture to sustain civilisation. In Land restoration: Reclaiming landscapes for a sustainable future, eds. I. Chabay, M. Frick, and J. Helgeson. ProQuest Ebook Central. Elsevier Science and Technology. https://ebookcentral.proquest.com.

Elevitch, C., D. Mazaroli, and D. Ragone. 2018. Agroforestry Standards of Regenerative Agriculture. Sustainability 10 (3337): 1-21. https://doi.org/10.3390/su10093337.

Ellis, N., and G. Albrecht. 2017. Climate change threats to family farmers' sense of place and mental wellbeing: A case study from the Western Australian Wheatbelt. Social Science and Medicine 175: 161-168. 
Fazey, I., P. Moug, S. Allen, K. Beckmann, D. Blackwood, M. Bonaventura, K. Burnett, et al. 2018. Transformations in a changing climate: A research agenda. Climate and Development 10 (3): 197-217.

Flynn, F. 2020. Genuine natural resources: A public square for ideas and action. https://www.linkedin.com/pulse/genuine-natur al-resources-public-square-ideas-action-frank-flynn/?track ingId $=$ rnFs $1 \mathrm{wv} 1 \mathrm{p} 0 \mathrm{zmKKHdrIomYA} \% 3 \mathrm{D} \% 3 \mathrm{D}$. Accessed 25 Sep 2020.

Foley, J., R. DeFries, G. Asner, C. Barford, G. Bonan, S. Carpenter, F. Chapin, et al. 2005. Global consequences of land use. Science 309 (5734): 570-574.

Foley, J., N. Ramankutty, K. Brauman, E. Cassidy, J. Gerber, M. Johnston, N. Mueller, et al. 2011. Solutions for a cultivated planet. Nature 478 (10452): 337-342.

Fowler, C., and P. Mooney. 1990. Shattering: Food, politics, and the loss of genetic diversity. Tucson: University of Arizona Press.

France, R. 2008. Handbook of regenerative landscape design. Boca Raton: CRC Press, Taylor and Francis Group.

Francis, C. 2016. The carbon farming solution: A global toolkit of perennial crops and regenerative agriculture practices for climate change mitigation and food security. Agroecology and Sustainable Food Systems 40 (9): 1039-1040. https://doi.org/10.1080/ 21683565.2016.1214861.

Francis, C., and R. Harwood. 1985. Enough food: Achieving food security through regenerative agriculture. Kutztown: Rodale Institute.

Fukuoka, M. 1978. The one-straw revolution. An introduction to natural farming. Emmaus: Rodale Press.

Fullerton, J. 2015. Regenerative capitalism: How universal principles and patterns will shape our new economy. New York: Capital Institute.

Gammage, W. 2011. The biggest estate on earth: HOw aborigines made Australia. Crows Nest: Allen \& Unwin.

Gerten, D., V. Heck, J. Jagermeyr, B. Bodirsky, I. Fetzer, M. Jalava, M. Kummu, et al. 2020. Feeding ten billion people is possible within four terrestrial planetary boundaries. Nature Sustainability 3 (3): 200-208

Gibbons, L. 2020. Regenerative-The new sustainable? Sustainability 12 (5483): 1-19. https://doi.org/10.3390/su12135483.

Gibbs, P., and A. Beavis. 2020. Contemporary thinking on transdisciplinary knowledge: What those who know, know. Cham: Springer.

Giller, K., R. Hijbeek, J. Andersson, and J. Sumberg. 2021. Regenerative Agriculture: An agronomic perspective. Outlook on Agriculture 50 (1): 13-25. https://doi.org/10.1177/0030727021998063.

Gleick, P. 2003. Water use. Annual Review of Environment and Resources 28 (1): 275-314.

Gliessman, S.R. 1990. Agroecology: Researching the ecological basis for sustainable agriculture. New York: Springer.

Gliessman, S.R. 2001. Agroecosystem Sustainability: Developing practical strategies. In Advances in agroecology, ed. S.R. Gliessman. Boca Raton: CRC Press.

Gliessman, S.R. 2007. Agroecology: The ecology of sustainable food systems, 2 Aufl. Boca Raton: CRC Press.

Goldstein, J. 1999. Emergence as a construct: History and issues. Emergence: Complexity and Organisation 1 (1): 49-72.

Gopal, M., A. Gupta, K. Hameed, N. Sathyaseelan, T. Rajeela, and G. Thomas. 2020. Biochars produced from coconut palm biomass residues can aid regenerative agriculture by improving soil properties and plant yield in humid tropics. Biochar 2 (2): 211-226. https://doi.org/10.1007/s42773-020-00043-5.

Gordon, L. 2021. Principles and practices of regenerative agriculture. In Farming matters: For our love of the land, ed. T. Hill. Albury: Land to Market Australia.

Gosnell, H., S. Charnley, and P. Stanley. 2020a. Climate change mitigation as a co-benefit of regenerative ranching: Insights from
Australia and the United States. The Royal Society Interface Focus. https://doi.org/10.1098/rsfs.2020.0027.

Gosnell, H., N. Gill, and M. Voyer. 2019. Transformational adaptation on the farm: Processes of change and persistence in transitions to 'climate-smart' regenerative agriculture. Global Environmental Change 59 (101965): 1-13.

Gosnell, H., K. Grimm, and B. Goldstein. 2020b. A half century of holistic management: What does the evidence reveal? Agriculture and Human Values 37: 849-867. https://doi.org/10.1007/ s10460-020-10016-w.

Gou, Z., and X. Xie. 2017. Evolving green building: Triple bottom line or regenerative design? Journal of Cleaner Production 153: $600-607$.

Graham, N., and R. Bartel. 2017. Farmscapes: Property, ecological restoration and the reconciliation of human and nature in Australian agriculture. Griffith Law Review 26 (2): 221-247.

Green, R., S. Cornell, J. Scharlemann, and A. Balmford. 2005. Farming and the fate of wild nature. Science 307 (5709): 550-555.

Grelet, G., S. Lang, C. Merfield, N. Calhoun, M. Robson-Williams, A. Horrocks, A. Dewes, et al. 2021. Regenerative agriculture in Aotearoa New Zealand-Research pathways to build sciencebased evidence and national narratives. New Zealand National Science Challenge Our Land and Water; The NEXT Foundation; Manaaki Whenua Landcare Research.

Haggard, B., and P. Mang. 2016. Regenerative development and design: A framework for evolving sustainability. Hoboken: Wiley.

Hajer, M.A. 1995. The politics of environmental discourse: Ecological modernization and the policy process. Oxford: Oxford University Press.

Hartle, D. 2016. The carbon farming solution: A global toolkit of perennial crops and regenerative agriculture practices for climate change mitigation and food security. Library Journal 141 (2): 94.

Hawken, P. 2017. Drawdown: The most comprehensive plan ever proposed to reverse global warming. New York: Penguin.

Henly, S. 2021. Soil health-Regeneration and renewal. The Farmer. https://thefarmermagazine.com.au/soil-health-leads-to-regenerati on-and-renewal/. Accessed 20 Jan 2021.

Hes, D., and C. du Plessis. 2015. Designing for hope: Pathways to regenerative sustainability. New York: Routledge.

Hes, D., and N. Rose. 2019. Shifting from farming to tending the earth: A discussion paper. Journal of Organics 6 (1): 3-22.

Hintz, C. 2015a. An ecology of love: Women farmers, sense of place, the Georgic ethic, and ecocentricity. Journal of Sustainability Education 9: 1-18.

Hintz, C. 2015b. Soil in my blood: Women farmers, transformative learning, and regenerative agriculture. Prescott: Prescott College ProQuest.

Hodbod, J., O. Barreteau, C. Allen, and D. Magda. 2016. Managing adaptively for multifunctionality in agricultural systems. Journal of Environmental Management 183: 379-388. https://doi.org/10. 1016/j.jenvman.2016.05.064.

Holmgren, D. 2007. Permaculture: Principles and pathways beyond sustainability, Revised Edition. Hepburn: Australia Melliodora Publishing.

Horrigan, L., R. Lawrence, and P. Walker. 2002. How sustainable agriculture can address the environmental and human health harm of industrial agriculture. Environmental Health Perspectives 110 (5): 445-545.

Houghton, R. 2018. Interactions between land-use change and climatecarbon cycle feedbacks. Current Climate Change Reports 4 (2): $115-127$.

Howard, Albert. 1940. An agricultural testament. London: Oxford University Press.

Howard, Albert. 2013. The soil and health: A study of organic agriculture. Swadhyay Mandir, Indore Banyan Tree. 
Howarth, R., D. Swaney, G. Billen, J. Garnier, B. Hong, C. Humborg, P. Johnes, C. Morth, and R. Marino. 2011. Nitrogen fluxes from the landscape are controlled by net anthropogenic nitrogen inputs and by climate. Frontiers in Ecology and the Environment 10 (1): 37-43.

Iles, A. 2020. Can Australia transition to an agroecological future? Agroecology and Sustainable Food Systems. https://doi.org/10. 1080/21683565.2020.1780537.

IPCC. 2019. Climate change and land: An IPCC special report on climate change, desertification, land degradation, sustainable land management, food security, and greenhouse gas fluxes in terrestrial ecosystems. Intergovernmental Panel on Climate Change.

Kearnes, M., and L. Rickards. 2020. Knowing earth, knowing soil: Epistemological work and the political aesthetics of regenerative agriculture. In Thinking with soils: Material politics and social theory, ed. J. Salazar and C. Granjou, 71-84. London: Bloomsbury Publishing.

Kimbrell, A. 2002. Fatal harvest: The tragedy of industrial agriculture. Washington, DC: Island Press.

Klein, J. 2015. Reprint of "Discourses of Transdisciplinarity: Looking back to the future." Futures 65: 10-16.

Knorr, D. 1984. Feasibility of analytical procedures and unit operations for the distinction between organic, natural or conventional foods. Biological Agriculture and Horticulture 2 (2): 183-194.

Koestler, A. 1967. The ghost in the machine. London: Hutchinson \& Co.

LaCanne, C., and J. Lundgren. 2018. Regenerative agriculture: Merging farming and natural resource conservation profitably. PeerJ 6: e4428. https://doi.org/10.7717/peerj.4428.

Lakoff, G. 2014. Don't think of an elephant: Know your values and frame the debate. White River Junction: Chelsea Green Publishing.

Lakoff, G., and M. Johnson. 2008. Metaphors we live by. Chicago: University of Chicago Press.

Lal, R. 2020. Regenerative agriculture for food and climate. Journal of Soil and Water Conservation 75 (5): 123A-A124. https://doi. org/10.2489/jswc.2020.0620A.

Lawrence, G., C. Richards, and K. Lyons. 2013. Food security in Australia in an era of neo-liberalism, productivism and climate change. Journal of Rural Studies 29: 30-39.

Lent, J. 2017. The patterning instinct. Amherst: Prometheus Books.

Leu, A. 2020. An overview of global organic and regenerative agriculture movements. In Organic food systems: Meeting the needs of Southern Africa, ed. R. Auerbach, 21-31. Wallingford: CABI.

Lindenmeyer, D. 2007. On borrowed time-Australia's environmental crisis and what we must do. Camberwell: Penguin Books.

Linnér, B., and V. Wibeck. 2020. Conceptualising variations in societal transformations towards sustainability. Environmental Science and Policy 106: 221-227.

Linnér, B., and V. Wibeck. 2019. Sustainability transformations: Agents and drivers across societies. Cambridge: Cambridge University Press.

Lipton, Bruce. 2005. The biology of belief: Unleashing the power of consciousness, matter, and miracles. Maryborough: Hay House Australia.

Loorbach, D., J. Wittmayer, F. Avelino, T. von Wirth, and N. Frantzeskaki. 2020. Transformative innovation and translocal diffusion. Environmental Innovation and Societal Transitions 35: 251-260.

Lowe, P., J. Murdoch, T. Marsden, R. Munton, and A. Flynn. 1993. Regulating the new rural space: The uneven development of land. Journal of Rural Studies 9 (3): 205-222.

Lyle, J. 1994. Regenerative design for sustainable development. New York: Wiley.

Mang, P., and B. Reed. 2012. Designing from place: A regenerative framework and methodology. Building Research and Information 40 (1): 23-38.
Mann, C., J. Parkins, M. Isaac, and K. Sherren. 2019. Do practitioners of holistic management exhibit systems thinking? Ecology and Society 24 (3): 19.

Mann, C., and K. Sherren. 2018. Holistic management and adaptive grazing: A trainer's view. Sustainability (Special Issue on Agroecology for the Transition Towards Socio-ecological Sustainability) 10 (6): 1848.

Massy, C. 2013. Transforming the earth: A study in the change of agricultural mindscapes. Canberra: Australian National University.

Massy, C. 2017. Call of the reed warbler: A new agriculture-A new earth. Brisbane: University of Queensland Press.

Maturana, H. 2002. Autopoiesis, structural coupling and cognition: A history of those and other notions in the biology of cognition. Cybernetics and Human Knowing 9 (3-4): 5-34.

Maturana, H., and F. Varela. 1980. Autopoiesis and cognition: The realisation of the living. Dordrecht: Reidel Publishing Company.

Maturana, H., and F. Varela. 1992. The tree of knowledge: The biological roots of human understanding. Boston: Shambhala Publications.

Max-Neef, M. 2005. Foundations of transdisciplinarity. Ecological Economics 1 (53): 5-16.

McDonald, D. 2017. We can raise cattle in regenerative agriculture. New Scientist 236 (3149): 54.

McIntyre, B., H. Herren, J. Wakhungu, and R. Watson. 2009. International assessment of agricultural knowledge, science and technology for development (IAASTD): Global report. Washington, DC: World Bank.

McKeon, N. 2015. Food security governance: Empowering communities, regulating corporations. New York: Routledge.

McNeill, J. 2000. Something new under the sun: An environmental history of the twentieth century world. New York: W.W. Norton.

Meadows, D. 2008. Leverage points: Places to intervene in a system. In Thinking in systems: A primer, ed. D. Wright. White River Junction: Chelsea Green Publishing.

Mills, General. 2020. From the ground up: Regenerative agriculture revives farmland while curbing climate change. https://www. Theguardian.Com/Soil-Matters/Ng-Interactive/2020/Jul/09/ Regenerative-Agriculture-Revives-Soil-Curbs-Climate-Change. Accessed 11 Nov 2020.

Moffat, A. 1998. Global nitrogen overload problem grows critical. Science 279 (5353): 988-989.

Mollison, B. 1988. Permaculture: A designers manual. Tasmania: Tagari Publications.

Morseletto, P. 2020. Restorative and regenerative: Exploring the concepts in the circular economy. Journal of Industrial Ecology 24: $763-773$.

Muller, E. 2020. Regenerative development as natural solution for sustainability. In The Elgar companion to geography, transdisciplinarity and sustainability, ed. F. Sarmiento and L. Frolich. Cheltenham: Edward Elgar Publishing.

Murphy, B.P., and D.M. Bowman. 2007. The interdependence of fire, grass, kangaroos and Australian Aborigines: A case study from central Arnhem Land, northern Australia. Journal of Biogeography 34 (2): 237-250.

Newton, P., N. Civita, L. Frankel-Goldwater, K. Bartel, and C. Johns. 2020. What is regenerative agriculture? A review of scholar and practitioner definitions based on processes and outcomes. Frontiers in Sustainable Food Systems 4: 577723. https://doi.org/10. 3389/fsufs.2020.577723.

Nicolescu, B. 2002. Manifesto of transdisciplinarity. Albany: State University of New York Press.

Obrien, K. 2018. Is the $1.5 \mathrm{C}$ target possible? Exploring the three spheres of transformation. Environmental Sustainability 31: $153-156$. 
Oldeman, L., R. Hakkeling, and W. Sombroek. 1991. World map of the status of human-induced soil degradation: An explanatory note. Wageningen: International Soil Reference and Information Centre and United Nations Environment Programme.

Park, J., S. Ale, W. Teague, and S. Downhower. 2017. Simulating hydrologic responses to alternate grazing management practices at the Ranch and watershed scales. Journal of Soil and Water Conservation 72 (2): 102-121.

Pascoe, Bruce. 2014. Dark emu black seeds: Agriculture or accident? Broome: Magabala Books.

Patagonia. 2020. Why regenerative organic? https://www.patagonia. com/regenerative-organic/ Accessed 10 June 2020.

Perceval, M., K. Kolves, V. Ross, P. Reddy, and D. De Leo. 2018a. Environmental factors and suicide in Australian farmers: A qualitative study. Archives of Environmental and Occupational Health 74 (5): 279-286.

Perceval, M., K. Kolves, V. Ross, P. Reddy, and D. De Leo. 2018b. Social factors and Australian farmer suicide: A qualitative study. BMC Public Health 18 (1): 1367.

Pimentel, D. 2005. Environmental and economic costs of the application of pesticides, primarily in the United States. Environment, Development and Sustainability 7 (2): 229-252.

Pimentel, D., A. McLaughlin, B. Zepp, T. Latikan, T. Kraus, F. Klienman, W. Vancini, et al. 1991. Environment and economic effects of reducing pesticide use. BioScience 41 (6): 402-409.

Pimentel, D., and M. Pimenel. 1996. Food, energy and society. Niwot: University of Colorado Press.

Pimm, S., C. Jenkins, R. Abell, T. Brooks, J. Gittleman, L. Joppa, P. Raven, C. Roberts, and J. Sexton. 2014. The biodiversity of species and their rates of extinction, distribution and protection. Science. https://doi.org/10.1126/science.1246752.

Pimm, S., and P. Raven. 2000. Biodiversity: Extinction by numbers. Nature 403 (6772): 843-844.

Plaut, J., and E. Amedee. 2018. Becoming a regenerative practitioner: A field guide. Colorado State University Institute for the Built Environment.

Plaut, J., B. Dunbar, A. Wackerman, and S. Hodgin. 2012. Regenerative design: The LENSES Framework for buildings and communities. Building Research and Information 40 (1): 112-122.

Poelina, A., C. Marshall, M. Graham, T. Yunkaporta, R. Williams, A. Marsh, and F. Blacklock. 2021. Regenerative Songlines Australia. https://www.regenerative-songlines.net.au. Accessed 12 June 2021.

Postel, S. 1996. Dividing the waters: Food security, ecosystem health, and the new politics of scarcity (Worldwatch paper no. 132). Washington, DC: Worldwatch Institute.

Provenza, F. 2008. What does it mean to be locally adapted and who cares anyway? Journal of Animal Science 86 (14 Suppl): E271E284. https://doi.org/10.2527/jas.2007-0468.

Provenza, F., H. Pringle, D. Revell, N. Bray, C. Hines, R. Teague, T. Steffens, and M. Barnes. 2013. Complex creative systems: Principles, processes, and practices of transformation. Rangelands 35 (5): 6-13.

Quarles, W. 2018. Regenerative agriculture can reduce global warming. IPM Practitioner 36 (1/2): 1-8.

Rhodes, C. 2012. Feeding and healing the world: Through regenerative agriculture and permaculture. Science Progress 94 (4): 345-446.

Rhodes, C. 2017. The imperative of regenerative agriculture. Science Progress 100 (1): 80-129.

Ridinger, R. 2016. Review of the carbon farming solution: A global toolkit of perennial crops and regenerative agriculture practices for climate change mitigation and food security. Journal of Agricultural and Food Information 17 (2-3): 200.

Riedy, C. 2020. Discourse coalitions for sustainability transformations: Common ground and conflict beyond neoliberalism. Current Opinion in Environmental Sustainability 45: 100-112.
Rockström, J., W. Steffen, K. Noone, A. Persson, F.S. Chapin III., E. Lambin, T.M. Lenton, et al. 2009a. Planetary boundaries: Exploring the safe operating space for humanity. Ecology and Society 14 (2): 32.

Rockström, J., W. Steffen, K. Noone, A. Persson, F.S. Chapin III., E. Lambin, T.M. Lenton, et al. 2009b. A safe operating space for humanity. Nature 461 (7263): 472-475.

Rockström, J., J. Williams, G. Daily, A. Noble, N. Matthews, L. Gordon, H. Wetterstrand, et al. 2016. Sustainable intensification of agriculture for human prosperity and global sustainability. Ambio 46: 1-14.

Romero-Briones, A., E. Salmon, H. Renick, and T. Costa. 2020. Recognition and support of Indigenous California land stewards, practitioners of kincentric ecology. In Nourishing native foods and health. First Nations Development Institute and California Foodshed Funders.

Rowell, A. 2003. Don't worry it's safe to eat: The true story of GM food, BSE and foot and mouth. London: Earthscan Publications Ltd.

Saldana, J. 2009. The coding manual for qualitative researchers. London: Sage Publications.

Salmon, E. 2000. Kincentric ecology: Indigenous perceptions of the human-nature relationship. Ecological Applications 10 (5): 1327-1332.

Salmon, E. 2020. Iwigara: The kinship of plants and people; American Indian ethnobotanical traditions and science. Portland: Timber Press, Inc.

Sanford, C. 2011. The responsible business: Reimagining sustainability and success. New York: Wiley.

Sanford, C. 2017. The regenerative business: Redesign work, cultivate human potential, achieve extraordinary outcomes. Boston: Nicholas Brealey Publishing.

Savory. 2020. Savory Institute. https://savory.global/. Accessed 12 June 2020.

Savory, A. 1988. Holistic resource management. Washington, DC: Island Press.

Savory, A., and J. Butterfield. 1999. Holistic management second edition: A new framework for decision making, 2nd ed. Washington, DC: Island Press.

Savory, A., and J. Butterfield. 2016. Holistic management third edition: A commonsense revolution to restore our environment, 3 Aufl. Washington, DC: Island Press.

Sayre, L. 2019. One size fits none: A farm girl's search for the promise of regenerative agriculture. Interdisciplinary Studies in Literature and Environment 26 (3): 832-833. https://doi.org/10. 1093/isle/isz073.

Scherr, S., S. Shames, and R. Friedman. 2012. From climate smart agriculture to climate smart landscapes. Agriculture and Food Security 1 (1): 12.

Schreefel, L., R. Schulte, I. de Boer, A. Pas Schrijver, and H. van Zanten. 2020. Regenerative agriculture-The soil is the base. Global Food Security 26: 100404. https://edepot.wur.nl/ 517920.

Scrutton, A., N. Jones, D. Akana, B. Begashaw, A. Capon, O. Gaffney, D. Jacob, et al. 2020. Our future on earth. Future Earth. www.futureearth.org/publications/our-future-on-earth.

Sherren, K., and C. Kent. 2017. Whose afraid of Allan Savory? Scientometric polarisation on holisitc management as competing understandings. Renewable Agriculture and Food Systems 34 (1): 77-92.

Smuts, J. 1973. Holism and evolution. Westport: Greenwood Press. Soloviev, E., and G. Landua. 2016. Levels of regenerative agriculture. Terra Genesis International. http://www.terra-genesis. com/wp-content/uploads/2017/03/Levels-of-RegenerativeAgriculture-1.pdf. 
Soto, R., M. Padilla, and J. de Vente. 2020. Participatory selection of soil quality indicators for monitoring the impacts of regenerative agriculture on ecosystem services. Ecosystem Services 45: 101-157. https://doi.org/10.1016/j.ecoser.2020.101157.

Springman, M., M. Clark, D. Mason D-Croz, K. Wiebe, B. Bodirsky, L. Lassaletta, W. de Vries, et al. 2018. Options for keeping the food system within environmental limits. Nature 562 (7728): 519-25.

Steffen, W., P. Crutzen, and J. McNeill. 2007. The Anthropocene: Are humans now overwhelming the great forces of Nature? Ambio 36 (8): 614-621.

Steffen, W., A. Persson, L. Deutsch, J. Zalasiewicz, M. Williams, K. Richardson, C. Crumley, and P. Crutzen. 2011. The Anthropocene: From global change to planetary stewardship. Ambio 40 (7): 739-761.

Steffen, W., K. Richardson, J. Rockström, S. Cornell, I. Fetzer, E. Bennett, R. Biggs, et al. 2015. Planetary boundaries: Guiding human development on a changing planet. Science 347 (6223): 1259855. https://doi.org/10.1126/science.1259855.

Steiner, R. 1993. Agriculture. Oregon: Bio-Dynamic Farming and Gardening Assoc. Inc.

Stuart, D., and R. Clemens. 2018. Regenerative agriculture takes root. Food Technology 72 (8): 18-9.

Sutton, P., and K. Walshe. 2021. Farmers or hunter-gatherers? The Dark Emu debate. Melbourne: Melbourne University Press.

Svec, P., R. Berkebile, and J. Todd. 2012. REGEN: Toward a tool for regenerative thinking. Building Research and Information 40 (1): 81-94.

Swaney, D., B. Hong, C. Ti, R. Howarth, and C. Humborg. 2012. Net anthropogenic nitrogen inputs to watersheds and riverine $\mathrm{N}$ export to coastal waters: A brief overview. Current Opinion in Environmental Sustainability 4 (2): 203-211.

Teague, R., and M. Barnes. 2017. Grazing management that regenerates ecosystem function and grazing land livelihoods. African Journal of Range and Forage Science 34 (2): 77-86.

Teague, R., and U. Kreuter. 2020. Managing grazing to restore soil health, ecosystem function, and ecosystem services. Frontiers in Sustainable Food Systems 4: 534187. https://doi.org/10.3389/ fsufs.2020.534187.

Thomas, C.D., A. Cameron, R.E. Green, M. Bakkenes, L. Beaumont, Y. Collingham, B. Erasmus, et al. 2004. Extinction risk from climate change. Nature 427 (6970): 145-148.

Tilman, D., K.G. Cassman, P.A. Matson, R. Naylor, and S. Polasky. 2002. Agricultural sustainability and intensive production practices. Nature 418 (6898): 671-677.

Toensmeier, E. 2016. The carbon farming solution: A global toolkit of perennial crops and regenerative agriculture practices for climate change mitigation and food security. White River Junction: Chelsea Green Publishing.

Tourangeau, W., and K. Sherren. 2020. Leverage points for sustainable wool production in the Falkland Islands. Journal of Rural Studies 74: 22-23.

Tourangeau, W., K. Sherren, C. Kent, and B. MacDonald. 2019. Of climate and weather: Examining Canadian farm and livestock organisation discourses from 2010 to 2015. Weather, Climate and Society 14 (1): 95-111.

United, Hawaii Farmers Union. 2020. Zach Bush MD Keynote: Hawaii Farmers Union United. Hawaii Farmers Union United. https:// www.youtube.com/watch?v=G8W7twV8O54.

Van der Ploeg, J. 2020. From biomedical to politico-economic crisis: The food system in times of COVID-19. The Journal of Peasant Studies 47 (5): 944-972.

Vermeulen, S., T. Park, C. Khoury, J. Mockshell, C. Béné, H. Thi, B. Heard, and B. Wilson. 2019. Changing diets and transforming food systems. CCAFS Working Paper No. 282. Wageningen:
CGIAR Research Program on Climate Change, Agriculture and Food Security (CCAFS).

Wahl, D.C. 2016. Designing regenerative cultures. Axminster: Triarchy Press.

Watson, J., M. Evans, J. Carwardine, R. Fuller, L. Joseph, D. Segam, M. Taylor, T. Fensham, and H. Possingham. 2010. The capacity of Australia's protected-area system to represent threatened species. Conservation Biology 25 (2): 324-332.

White, C. 2008. Revolution on the range: The rise of a new ranch in the American West. Washington, DC: Island Press.

White, C. 2020. Why regenerative agriculture? The American Journal of Economics and Sociology 79 (3): 799-812.

Wilber, Ken. 2001. Sex, ecology, spirituality: The spirit of evolution. Boston: Shambhala Publications.

Wood, S., K. Sebastian, and S. Scherr. 2000. Pilot analysis of global ecosystems: Agroecosystems. Washington, DC: International Food Policy Research Institute and World Resources Institute.

WRI. 2005. Millennium ecosystem assessment 2005. Ecosystems and human well-being: Biodiversity synthesis. Washington, DC: World Resources Institute.

Yeomans, P. 1993. Water for every farm: Yeomans keyline plan. Netley: Griffin Press Pty. Ltd.

Zari, M. 2012. Ecosystem services analysis for the design of regenerative built environments. Building Research and Information 40 (1): 54-64.

Zari, M. 2015. Ecosystem services analysis: Mimicking ecosystem services for regenerative urban design. International Journal of Sustainable Built Environment 4 (1): 145-157.

Zhang, W., T.H. Ricketts, C. Kremen, K. Carney, and S.M. Swinton. 2007. Ecosystem services and dis-services to agriculture. Ecological Economics 64 (2): 253-260.

Zimmer, G.F. 2000. The biological farmer: A complete guide to the sustainable and profitable biological system of farming. Austin: Acres USA.

Publisher's Note Springer Nature remains neutral with regard to jurisdictional claims in published maps and institutional affiliations.

Ethan Gordon is a $\mathrm{PhD}$ Candidate at the Institute for Sustainable Futures, University of Technology Sydney. He uses critical discourse analysis and action research for transformations to explore regenerative agriculture and other ecological alternatives to extractive agricultural models. He also runs a steer trading and carbon farming operation with his family. Through holistic management, their grazing animals are utilised for carbon sequestration.

Federico Davila is a Research Director in Food Systems at the Institute for Sustainable Futures, University of Technology Sydney. His research focuses on the theory and practice of systems-based approaches to sustainable food systems. He specialises on human ecology, systems methodologies, and transdisciplinary approaches for Australian and Pacific Islands' food systems.

Chris Riedy is Professor of Sustainability Transformations at the Institute for Sustainable Futures, University of Technology Sydney. He is a transdisciplinary academic with a research interest in governance, communication and social change for sustainability. Chris draws on sociological and political theory, narrative theory and futures thinking to design, facilitate and evaluate practical experiments in transformative change towards sustainable futures. 